\title{
Caesarean Section Delivery and Risk of Poor Childhood Growth
}

\author{
Mahama Saaka (D) and Addae Yaw Hammond \\ University for Development Studies, School of Allied Health Sciences, P.O. Box TL 1883, Tamale, Ghana \\ Correspondence should be addressed to Mahama Saaka; mmsaaka@gmail.com
}

Received 5 November 2019; Accepted 10 April 2020; Published 1 May 2020

Academic Editor: C.S. Johnston

Copyright (C) 2020 Mahama Saaka and Addae Yaw Hammond. This is an open access article distributed under the Creative Commons Attribution License, which permits unrestricted use, distribution, and reproduction in any medium, provided the original work is properly cited.

\begin{abstract}
Background. Though emerging evidence indicates caesarean section (CS) brings about late initiation of breastfeeding, early cessation of breastfeeding, and a higher risk of developing obesity, little is documented on the association between CS birth and stunted growth. This study assessed caesarean section delivery and the risk of poor postnatal childhood growth. Methods. A retrospective cohort study design was used to collect the requisite data on a sample of 528 mothers having children between the ages of 6 to 24 months. An interviewer-administered questionnaire was used to collect the data. Results. After controlling for potential confounding factors, linear growth as measured by height-for-age Z-score (HAZ) was significantly higher by 0.121 standard units in children born through normal vaginal delivery, compared to their counterparts born through caesarean section (beta coefficients $(\beta)=0.121, p=0.002$ ). The mode of delivery also had a statistically significant impact on infant feeding practices. Whereas $70.4 \%$ of babies delivered via vagina initiated breastfeeding within one hour of delivery, only $52.7 \%$ of babies born through CS did the same. Vaginally delivered babies were 2.1 times more likely to initiate breastfeeding within one hour of delivery $(($ Crude odds ratio $(C O R)=2.13, p<0.001)$. Compared to CS babies, vaginally delivered babies were 3.2 times more likely not to have been fed with prelacteal feeds such as water and sugar solutions. Vagina delivered babies were 1.8 times more likely to receive adequate neonatal feeding than their counterparts who were delivered through CS $(\mathrm{COR}=1.76, p=0.003)$. Conclusions. This study has found an association between CS delivery and stunting, an adverse outcome that clinicians and patients should weigh when considering in particular elective CS that seeks to avoid the pain associated with a vaginal birth.
\end{abstract}

\section{Background}

Stunted child growth or poor linear growth (height for age $\mathrm{Z}$-score 2 standard deviations below the median of the WHO reference population) remains a major public health problem in most places especially in deprived communities [1]. As of 2017, nearly 151 million (22\%) children under five years old were stunted [2], and this accounts for $35-45 \%$ of worldwide deaths among children less than five years old $[1,3]$. By virtue of the adverse consequences of stunted growth, it has been targeted to be reduced globally among children under five by $40 \%$ by 2025 [4].

As reported in the 2008 Lancet series on maternal and childhood undernutrition, Ghana was classified among the 36 countries in the world with the highest burden of chronic childhood undernutrition [5]. In Ghana, there has been a slow reduction in stunting rates, where it reduced nationally from $35 \%$ in 2003 to $19 \%$ in 2014 but the current prevalence of stunting in Northern Region of Ghana which stands at $33 \%$ [6] is above internationally acceptable levels.

Global assessment of stunting in low- and middle-income countries revealed that the causes of stunting are multifaceted including poor nutrition, infectious diseases, and household environment [7] and that growth restriction in utero and lack of access to sanitation are the main drivers of stunting [8]. Though a multitude of risk factors has been documented, these vary from place to place and, therefore, context specific. Furthermore, a full understanding of these factors and their relative effect is key to help priority setting in designing policies and interventions to improve childhood growth.

In recent years, another health issue, which experts have expressed worry about, is the rise in caesarean section (CS) childbirths which could have possible negative consequences 
for maternal and infant nutritional outcomes. CS is an important medical procedure for saving infant and maternal lives in emergency obstetric circumstances and has helped reduce maternal and neonatal morbidity and mortality particularly when medically indicated [9], but it has been on the rise globally. Some health experts have questioned whether CS prevalence beyond recommended levels has any additional benefits to the populace. The most common recommended threshold is the 15\% upper limit and $10 \%$ lower limit suggested by the World Health Organization (WHO) in 1985.

In Ghana, CS has been on the increase similar to global trends. In 2003, the rate was $3.7 \%$, and as of 2014, it rose to $13 \%$. These levels vary with respect to regions and some recording as high as $23 \%[6,10]$. A CS rate of $13 \%$ is above the lower safe limit of $10 \%$ suggested by the WHO and is particularly worrying when juxtaposed with other recommended thresholds such as that of Ye et al. [11], who suggested that the acceptable rate for CS should be $5 \%$ to $10 \%$ and "caesarean section rates higher than $10 \%$ at the population level are not associated with decreases in maternal and neonatal mortality rates."

When CS is medically indicated, it undeniably saves lives but the high prevalence of low-risk women taking the surgery is unnecessary. It implies that women and neonates are being exposed to avoidable risks as well as increasing the burden of cost on health systems [12].

Though emerging evidence indicates that CS brings about late initiation of breastfeeding, early cessation of breastfeeding, higher risk of developing obesity, among others [13-19], very few studies, if any, have been conducted to assess the association between caesarean section and stunting. In Northern Ghana where stunting rates remain high with the attendant increase in CS deliveries, no study as yet investigated the effects of CS on nutritional outcomes such as growth. It is this knowledge gap that this study sought to explore and fill. To better understand the persisting challenges of reducing stunting, we assessed the prevalence of caesarean section delivery and its relationship with the risk of stunting in childhood. It is hoped that findings from this study will help shed light on and support research-based policy suggestions with a view of addressing problems of the high prevalence of malnutrition amid increasing rates of CS globally.

\section{Materials and Methods}

2.1. Study Design, Population, and Sampling. A retrospective cohort study design was used to collect the requisite data. Mothers of children between the ages of 6 to 24 months were selected systematically from six health institutions that provide the Child Welfare Clinic (CWC) services. The attendance registers which served as the sampling frame were used to select two groups of eligible respondents: the nonexposed group comprising women whose index child was delivered without CS and the exposed group comprising women who delivered the index child through CS.

A minimum sample size of 482 (241 per study arm) was needed in order to have an $80 \%$ power of detecting a significant difference of $8 \%$ in the primary outcome measure between the study groups at $95 \%$ confidence interval, and making provision of $10 \%$ contingency, the sample size was adjusted to 530. However, 528 mother and child pairs took part in this study which comprised 242 that had caesarean section and 286 mothers having a normal delivery.

2.2. Data Collection. A structured pretested questionnaire was used to collect quantitative data. One-to-one interviews were conducted and other vital information was extracted from antenatal records booklet.

2.3. Independent and Dependent Variables. The main outcome measure was the low height for age (stunting). The exposure or independent variable was the mode of delivery (that is, caesarean section or normal delivery). A brief description of how some of these variables were measured is as follows.

2.4. Dependent Variable: Stunting (Low Height for Age). Chronic malnutrition (stunting) was measured as low height-for-age Z-scores (HAZ) [20]. The height-for-age Z-score, as defined by the WHO, expresses a child's height in terms of the number of standard deviations above or below the median height of healthy children in the same age group or in a reference group. Stunted children were those having their height-for-age Z-score 2 standard deviations below the median of the WHO reference population.

2.5. Potential Confounding Factors. Other potential confounding variables measured in the study were sociodemographic characteristics including the age of child and mother, parity, marital status, religion, educational background of mothers and household wealth index the socioeconomic status of the mother, the nutritional status of the mother measured as body mass index (BMI), the fathers' occupation and occupational status, the mothers' formal educational status, the immunization status of the child, birth weight of the child, the number of antenatal care (ANC) visits before birth, the duration of the pregnancy, APGAR score, the place of delivery, the number of children under five in household and mother's breastfeeding status, duration of breastfeeding, childhood illnesses such as acute respiratory infection during two weeks preceding the study, and household wealth index.

Household wealth index was quantified as a score of household assets such as ownership of means of transport, ownership of durable goods, and household facilities which were weighted using the principal components analysis method [21]. A brief description of the main independent and dependent variables is as follows.

2.6. Anthropometric Measurement. Anthropometric measurements of length and weight were obtained following standardized techniques and equipment. The length of the infants (6-23 months) was measured to the nearest $0.1 \mathrm{~cm}$ in a recumbent (lying) position using a horizontal wooden 
length board and movable headpiece (infantometer). The height was measured in older children in standing position. The weight in light clothes was obtained using a digital weighing scale (SECA 890) to the nearest $0.1 \mathrm{~kg}$. Anthropometric indicators of height for age (HAZ), weight for age (WAZ), and weight for height (WHZ) were determined as recommended by the WHO [22].

2.7. Data Quality Control Measures. Data collectors and supervisors were trained for two days prior to data collection in line with the objectives. The content of the training included the aim of the study, survey methodology including the selection of eligible participants, data recording, administration of questionnaires, and the art of interviewing and supervision.

The standardization test was carried out during the training to ensure that participants were well equipped with the requisite skills for the anthropometric measurement. The study questionnaire was also pretested and validated in 5\% of mothers/caregivers that were not part of the study sample.

2.8. Data Management and Analyses. Data cleaning and analysis were carried out using SPSS for Windows 22.0 (SPSS Inc., Chicago).

The Emergency Nutrition Assessment (ENA) for SMART software (2010 version) was used for the anthropometric data analysis and reported using WHO 2006 growth reference values with Standardized Monitoring and Assessment of Relief and Transitions (SMART) cut-offs.

A comparative analysis was carried out between normal vaginal and caesarean delivery on postnatal child growth. We conducted two-step hierarchical multiple regression analyses to determine independent predictors of height for age of children under two years. Multicollinearity was investigated by using the variance inflation factor (VIF). VIF (the reciprocal of the tolerance statistics) of greater than 5 is generally considered evidence of multicollinearity.

Explanatory variables that were significant at bivariate analysis at a $p$ value of 0.05 or less were fed into the regression model after confirming the absence of multicollinearity between these independent variables.

2.9. Ethics Consideration. The study protocol was approved by the Scientific Review and Ethics Committee of the School of Allied Health Sciences, University for Development Studies, Ghana. The ethics aspects of the study were also reviewed by the same scientific review committee that reviewed the study protocol. Informed written consent was obtained from the literate participants who were also provided copies of the signed forms for their records. In situations, where the participants could not write or read, verbal informed consent was sought after providing the needed information and explanation.

\section{Results}

3.1. Sociodemographic Characteristics of Respondents. Five hundred and fifty-eight mother and child pairs took part in this study which comprised 242 (45.8\%) that had caesarean section and $286(54.2 \%)$ mothers having a normal vaginal delivery. The mean age of the exposed mothers is $28.65 \pm 5.72$ while that of the nonexposed group is $26.99 \pm 5.89$. The mean age (months) of the children for the exposed group is $12.81 \pm 4.9$ and that of the nonexposed group is $12.00 \pm 4.43$. More (66.0\%) younger ( $<25$ years) respondents had normal delivery while women who had caesarean delivery were more likely to be of the elderly ( 34 years +). Those with higher education (at least SHS) and high wealth index were more likely to have been exposed to CS, $60.1 \%$ and $52.4 \%$, respectively.

At baseline, there were significant differences between the study groups with respect to the age of mother, maternal educational level, the timing of the first ANC visit, and household wealth index (Table 1).

\subsection{Comparison of Child Growth Indicators according to the} Mode of Delivery. This study aimed to determine whether caesarean delivery is a risk factor for stunting in children aged 6-24 months. The child's growth rate (g/month) was calculated based on the following formula: growth rate= current weight $(\mathrm{g})$-birthweight (g)/age (months). The mean child's growth rate was $455.1 \pm 158.2$ (g/month) among children aged 6-24 months.

The results show that caesarean delivery was associated negatively with the height-for-age $Z$-score of the child but not with the mean birth weight and weight-for-height $Z$ score. Children who were born through caesarean section (CS) had lower mean HAZ, compared to their counterparts who were born normally through the vagina (Table 2). There was no significant association between caesarean delivery and the other growth indicators, i.e., birth weight (g), weight for height, weight for age, and growth rate.

When the height-for-age Z-scores were treated as a categorical variable, the prevalence of stunted growth was still significantly higher among children born through caesarean delivery (49.2 versus $31.1 \%)$ (Chi-squared $=17.9$, $p<0.001)$.

3.3. Predictors of Height-for-Age Z-Score (HAZ): Multivariable Regression Analysis. After controlling for potential confounding factors, children who were born through normal vaginal delivery had 0.121 standard units higher HAZ than their counterparts born through caesarean section $(p<0.0001)$. Table 3 shows the "coefficients" table with the predictors which were statistically significant.

Considering the beta coefficients $(\beta)$, children of at least third birth order had mean HAZ which was 0.491 standard units significantly lower than their counterparts who were first born (beta $=[-0.491(95 \% \mathrm{CI}:-1.11$ to -0.44$))$. A unit increase in the age of child led to reduced HAZ of 0.206 standard units. The strongest predictor of mean HAZ was parity of the mother $(>2)$ with a standardized beta $(\beta)$ weight of $0.391, p<0.001$. The second highest contributor was the birth weight of the child with beta $(\beta)$ weight $=0.356$, $p<0.001$. A unit increase in maternal height led to increased 
TABLE 1: Comparison of sociodemographic characteristics by study groups $(N=528)$.

\begin{tabular}{|c|c|c|c|c|}
\hline \multirow[b]{2}{*}{ Variable } & \multicolumn{3}{|c|}{ Study groups } & \multirow[b]{2}{*}{ Test statistic } \\
\hline & $N$ & $\begin{array}{c}\text { Caesarean delivery } \\
n(\%)\end{array}$ & $\begin{array}{c}\text { Normal delivery } \\
n(\%)\end{array}$ & \\
\hline \multicolumn{5}{|l|}{ Age of mother (years) } \\
\hline Under 25 & 162 & $55(34.0)$ & $107(66.0)$ & \multirow{3}{*}{$\chi^{2}=13.3, p=0.001$} \\
\hline $25-34$ & 306 & $157(51.3)$ & $149(48.7)$ & \\
\hline $35+$ & 60 & $30(50.0)$ & $30(50.0)$ & \\
\hline \multicolumn{5}{|l|}{ Maternal education } \\
\hline None & 184 & $66(35.9)$ & $118(64.1)$ & \multirow{3}{*}{$\chi^{2}=27.2, p<0.001$} \\
\hline Low (primary \& JHS) & 141 & $54(38.3)$ & $87(61.7)$ & \\
\hline High (at least SHS) & 203 & $122(60.1)$ & $81(39.9)$ & \\
\hline \multicolumn{5}{|l|}{ Marital status } \\
\hline Married & 513 & $237(46.2)$ & $276(53.8)$ & \multirow{2}{*}{$\chi^{2}=0.9, p=0.3$} \\
\hline Single & 15 & $5(33.3)$ & $10(66.7)$ & \\
\hline \multicolumn{5}{|l|}{ Religion } \\
\hline Islam & 494 & $224(45.3)$ & $270(54.7)$ & \multirow{2}{*}{$\chi^{2}=0.7, p=0.4$} \\
\hline Christianity & 34 & $18(52.9)$ & $16(47.1)$ & \\
\hline \multicolumn{5}{|l|}{ Trimester of first ANC visit } \\
\hline 1-3 months & 367 & $180(49.0)$ & $187(51.0)$ & \multirow{2}{*}{$\chi^{2}=5.7, p=0.02$} \\
\hline$>3$ months & 159 & $60(37.7)$ & $99(62.3)$ & \\
\hline \multicolumn{5}{|l|}{ Frequency of ANC visits } \\
\hline Less than 4 & 8 & $5(62.5)$ & $3(37.5)$ & \multirow[t]{2}{*}{$\chi^{2}=0.9, p=0.3$} \\
\hline At least 4 & 512 & $233(45.5)$ & $279(54.5)$ & \\
\hline \multicolumn{5}{|l|}{ Classification of parity } \\
\hline Primiparous & 160 & $72(45)$ & $88(55.0)$ & \multirow{3}{*}{$\chi^{2}=2.0, p=0.4$} \\
\hline Secundiparous & 161 & $81(50.3)$ & $80(49.70)$ & \\
\hline Multiparous & 207 & $89(43.0)$ & $118(57.0)$ & \\
\hline \multicolumn{5}{|c|}{ Classification of wealth index } \\
\hline Low & 280 & $112(40.0)$ & $168(60.0)$ & \multirow{2}{*}{$\chi^{2}=8.2, p=0.004$} \\
\hline High & 248 & $130(52.4)$ & $118(47.6)$ & \\
\hline \multicolumn{5}{|l|}{ Employment status } \\
\hline Unemployed & 112 & $45(40.2)$ & $67(59.8)$ & \multirow{2}{*}{$\chi^{2}=1.8, p=0.2$} \\
\hline Employed & 416 & $197(47.4)$ & $219(52.6)$ & \\
\hline
\end{tabular}

TABLE 2: Comparison of child growth indicators according to mode of delivery.

\begin{tabular}{|c|c|c|c|c|c|c|c|}
\hline \multirow{2}{*}{$\begin{array}{l}\text { Categories of maternal } \\
\text { height }(\mathrm{cm})\end{array}$} & \multirow{2}{*}{ Child growth indicator } & \multirow{2}{*}{$N$} & \multirow{2}{*}{ Mean } & \multirow{2}{*}{$\begin{array}{c}\text { Std. } \\
\text { Deviation }\end{array}$} & \multicolumn{2}{|c|}{$\begin{array}{l}95 \% \text { confidence interval } \\
\text { for mean }\end{array}$} & \multirow{2}{*}{ Test statistic } \\
\hline & & & & & $\begin{array}{l}\text { Lower } \\
\text { bound }\end{array}$ & $\begin{array}{l}\text { Upper } \\
\text { bound }\end{array}$ & \\
\hline Vaginal delivery & \multirow{2}{*}{ Birth weight of child (g) } & 286 & 2967.34 & 502.03 & 2908.91 & 3025.77 & $F(1,524)=1.628$ \\
\hline Caesarean delivery & & 242 & 2906.78 & 588.78 & 2832.22 & 2981.33 & $p=0.20$ \\
\hline Vaginal delivery & \multirow{2}{*}{ Height for age of child } & 283 & -1.47 & 1.26 & -1.62 & -1.32 & $F(1,524)=10.569$, \\
\hline Caesarean delivery & & 242 & -1.84 & 1.36 & -2.01 & -1.67 & $p=0.001$ \\
\hline Vaginal delivery & \multirow{2}{*}{ Weight for height of child } & 282 & -0.59 & 1.12 & -0.72 & -0.46 & $F(1,524)=2.047$ \\
\hline Caesarean delivery & & 241 & -0.45 & 1.15 & -0.59 & -0.30 & $p=0.15$ \\
\hline Vaginal delivery & \multirow{2}{*}{ Weight for age of child } & 286 & -1.45 & 1.13 & -1.58 & -1.32 & $F(1,524)=0.988$, \\
\hline Caesarean delivery & & 242 & -1.55 & 1.21 & -1.71 & -1.40 & $p=0.32$ \\
\hline Vaginal delivery & \multirow{2}{*}{$\begin{array}{l}\text { Growth rate of child in } \\
\text { grams/month }\end{array}$} & 286 & 459.23 & 148.26 & 441.97 & 476.48 & $F(1,524)=0.416$ \\
\hline Caesarean delivery & & 242 & 450.31 & 169.46 & 428.85 & 471.76 & $p=0.52$ \\
\hline
\end{tabular}

HAZ of 0.245 standard units (beta $(\beta)=0.245$ (95\% CI: 0.04 , $0.07)$ ).

Female children had a mean HAZ that was significantly higher by 0.133 standard units (beta $\beta=0.245$, $p=0.001)$ and children born to women aged at least 35 years had a higher mean HAZ of 0.129 standard units, compared to children born to women under 25 years (beta $\beta=0.129, p=0.004)$. The set of variables accounted for $26.1 \%$ of the variance in mean HAZ (adjusted $R$ squared $=0.261$ ).

Using the hierarchical multiple regression approach, the covariate predictor variables (main effects) were entered in 
Table 3: Predictors of height-for-age Z-score (HAZ).

\begin{tabular}{lcccccc}
\hline \multirow{2}{*}{ Model } & \multicolumn{2}{c}{ Standardized coefficients } & \multicolumn{2}{c}{$95.0 \%$ confidence interval for $\beta$} & \multicolumn{2}{c}{ Collinearity statistics } \\
& Beta & $\mathrm{T}$ & Sig. & Lower bound & Upper bound & Tolerance \\
VIF
\end{tabular}

the first step. In the second step, the main explanatory variable of interest (that is, the mode of delivery) was added.

The percentage of variability in the dependent variable that can be accounted for by all the predictors together is measured by $\mathrm{R}$-squared. The change in $R^{2}$ is a way to evaluate how much predictive power was added to the model by the addition of another variable. In step 2 when the main explanatory variable was added to the model, the percentage of variability accounted for went up from $25.8 \%$ to $27.2 \%\left(R^{2}\right.$ Change $=0.014, p<0.001)$.

3.4. Relationship between Mode of Delivery and Neonatal Feeding Practices. To characterize infant feeding practices, we computed a composite infant feeding index (IFI) comprising current breastfeeding status of the child, timely initiation of breastfeeding within one hour, bottle feeding in the past 24 hours, prelacteal feeding, the introduction of complementary foods at 6 months, and feeding colostrum to the child.

Each positive practice/health behaviour was assigned a score of 1; otherwise, a score of zero was assigned. For example, a child receiving colostrum was a positive practice and so a score of 1 was given. Children who were bottle-fed or received prelacteal feed was score zero. A child meeting 5-6 of these practices was described as having appropriate infant feeding, and scores less than 5 criteria were classified as having inappropriate infant feeding.

The mean infant feeding index (IFI) for infants born through normal vaginal delivery was significantly higher than that for infants born through CS (5.0 versus 4.7$)$ ( $F$ $(1,527)=10.55, p=0.001)$.

From Table 4, the results showed that the mode of delivery was associated with the overall infant feeding index, timely initiation of breastfeeding within one hour, and prelacteal feeding. Infants delivered by caesarean section were less likely of being fed appropriately.
Whereas $70.4 \%$ of babies delivered via vagina initiated breastfeeding within one hour of delivery, only $52.7 \%$ of babies born through CS did the same. Vagina delivered infants were 2.1 times more likely to practice this behaviour. Compared to CS babies, vaginally delivered babies were 3.2 times more likely not to have been fed with prelacteal feeds such as water and sugar solutions. Vagina delivered babies were 1.8 times more likely to receive adequate neonatal feeding than their counterparts who were delivered through CS $(\mathrm{COR}=1.76, p=0.003)$.

3.5. Factors Associated with Mode of Delivery. As shown in Table 5, older women of at least 25 years were more likely to have caesarean delivery (CS). Women of the high educational level of at least Senior High School (SHS) were more likely to have caesarean delivery. Women who initiated ANC early within the first trimester of pregnancy were more likely to have caesarean delivery. CS operation was more common among women whose baby's birth weight was less than $2.5 \mathrm{~kg}$, compared to babies of weight at least $2.5 \mathrm{~kg}(63.2 \%$ versus $42.4 \%, p<0.001)$. Caesarean delivery was also common in households of high wealth index and women who had previous CS were more likely to have a delivery through CS. Overweight and obese women were prone to CS delivery.

Multivariable logistic regression analyses showed that systolic BP at 36 weeks of gestation, birth order, educational level of the mother, maternal height, mother's age, and having obstetric abnormalities during pregnancy were factors contributing significantly to caesarean section delivery (Table 6). Compared to mothers who initiated antenatal care beyond the first trimester, a greater proportion of women who initiated ANC in the first trimester had caesarean delivery $(\mathrm{OR}=1.98, \mathrm{CI}=1.10-3.55)$.

Compared to third-order babies, first- and second-order babies were 2.3 and 2.4 times more likely of being delivered 
TABLE 4: Relationship between the mode of delivery and infant feeding practices.

\begin{tabular}{lccc}
\hline Infant feeding practice & \multicolumn{2}{c}{ Mode of delivery } \\
& Caesarean & $n(\%)$ & Vaginal \\
$n(\%)$ & Crude odds ratio COR (CI) \\
\hline Timely initiation of breast feeding within one hour & $116(52.7)$ & $183(70.4)$ & $2.13(1.46-3.10), p<0.001$ \\
No bottle feeding in the past 24 hours & $201(83.1)$ & $237(82.9)$ & $0.9(0.63-1.56), p=0.9$ \\
No prelacteal feeding & $207(87.7)$ & $272(95.8)$ & $3.2(1.58-6.37), p=0.001$ \\
Introduction of complementary foods at 6 months & $150(62.0)$ & $188(65.7)$ & $1.18(0.08-1.03), p=0.06$ \\
Child received colostrum & $239(98.8)$ & $274(95.8)$ & $0.29(1.62-7.90), p=0.002$ \\
Adequate neonatal feeding & $150(62.0)$ & $212(74.1)$ & $1.76(1.21-2.55), p=0.003$ \\
\hline
\end{tabular}

TABLe 5: Factors associated with mode of delivery $(N=528)$.

\begin{tabular}{|c|c|c|c|c|}
\hline \multirow{2}{*}{ Factor } & \multirow{2}{*}{$N$} & \multicolumn{2}{|c|}{ Mode of delivery } & \\
\hline & & Caesarean delivery $n(\%)$ & Vaginal delivery $n(\%)$ & \\
\hline \multicolumn{5}{|l|}{ Age of mother (years) } \\
\hline Under 25 & 162 & $55(34.0)$ & $107(66.0)$ & \multirow{3}{*}{$\begin{array}{c}\text { Chi-squared }\left(\chi^{2}\right)=13.3 \\
p=0.001\end{array}$} \\
\hline $25-34$ & 306 & $157(51.3)$ & $149(48.7)$ & \\
\hline $35^{+}$ & 60 & $30(50.0)$ & $30(50.0)$ & \\
\hline \multicolumn{5}{|l|}{ Maternal education } \\
\hline None & 184 & $66(35.9)$ & $118(64.1)$ & \multirow{3}{*}{$\chi^{2}=27.2, p<0.001$} \\
\hline Low (primary \& JHS) & 141 & $54(38.3)$ & $87(61.7)$ & \\
\hline High (at least SHS) & 203 & $122(60.1)$ & $81(39.9)$ & \\
\hline \multicolumn{5}{|c|}{ Classification of household wealth index } \\
\hline Low $(<$ median score $)$ & 280 & $112(40.0)$ & $168(60.0)$ & \multirow{2}{*}{$\chi^{2}=8.2, p=0.004$} \\
\hline High (at least median score) & 248 & $130(52.4)$ & $118(47.6)$ & \\
\hline \multicolumn{5}{|c|}{$\begin{array}{l}\text { Had obstetric abnormalities during } \\
\text { pregnancy }\end{array}$} \\
\hline No & 400 & $165(41.3)$ & $235(58.8)$ & \multirow{2}{*}{$\chi^{2}=13.9, p<0.001$} \\
\hline Yes & 128 & $77(60.2)$ & $51(39.8)$ & \\
\hline \multicolumn{5}{|l|}{ Adequacy of ANC visits } \\
\hline No & 157 & $61(38.9)$ & $96(61.1)$ & \multirow{2}{*}{$\chi^{2}=4.3, p=0.04$} \\
\hline Yes & 363 & $177(48.8)$ & $186(51.2)$ & \\
\hline \multicolumn{5}{|l|}{ Timing of first ANC visit } \\
\hline $1-3$ months & 367 & $180(49.0)$ & $187(51.0)$ & \multirow{2}{*}{$\chi^{2}=5.7, p=0.02$} \\
\hline$>3$ months & 159 & $60(37.7)$ & $99(62.3)$ & \\
\hline \multicolumn{5}{|l|}{ Birth weight } \\
\hline$\geq 2.5 \mathrm{~kg}$ & 441 & $187(42.4)$ & $254(57.6)$ & \multirow{2}{*}{$\chi^{2}=12.7, p<0.001$} \\
\hline$<2.5 \mathrm{~kg}$ & 87 & $55(63.2)$ & $32(36.8)$ & \\
\hline \multicolumn{5}{|l|}{ Previous caesarean section } \\
\hline No & 456 & $170(37.3)$ & $286(62.7)$ & \multirow{2}{*}{$\chi^{2}=98.5, p<0.001$} \\
\hline Yes & 72 & $72(100.0)$ & $0(0.0)$ & \\
\hline \multicolumn{5}{|l|}{ Maternal BMI } \\
\hline Underweight & 22 & $7(31.8)$ & $15(68.2)$ & \multirow{4}{*}{$\chi^{2}=15.2, p=0.002$} \\
\hline Normal & 285 & $114(40.0)$ & $171(60.0)$ & \\
\hline Overweight & 160 & $85(53.1)$ & $75(46.9)$ & \\
\hline Obese & 58 & $36(62.1)$ & $22(37.9)$ & \\
\hline
\end{tabular}

through caesarean section $(\mathrm{AOR}=2.29$ and 2.39, respectively).

The data showed that a unit increase in maternal height led to $9 \%$ protection against CS delivery (AOR 0.91; 95\% CI (0.87-0.95)). Women who had obstetric abnormalities during pregnancy were 2.7 times more likely to have CS (AOR 2.68; 95\% CI (1.39-5.16)), compared to their counterparts who had no such problems.

Caesarean section rates tend to be higher among more educated women (AOR 2.94; 95\% CI (1.49-5.84)).

The set of predictors accounted for $29.5 \%$ of the variation in the mode of delivery (Nagelkerke $R$-squared $=0.295$ ).

\section{Discussion of Results}

We investigated the association between caesarean section (CS) birth and the risk of undernutrition among children aged 6-24 months. The main finding was that after controlling for potential confounding factors, children who were born through normal vaginal delivery had 0.121 higher HAZ than their counterparts born through caesarean section $(p<0.0001)$. However, results show no significant association between caesarean delivery and the other growth indicators such as birth weight, weight for height, weight for age, and growth rate. 


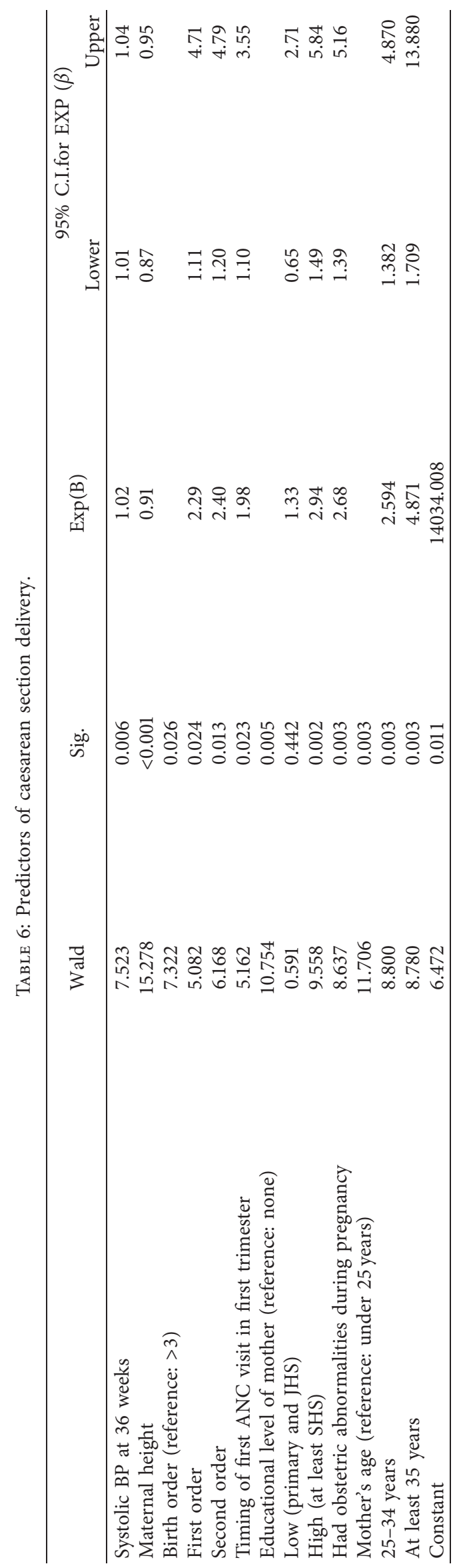


4.1. The Association between CS and Child Growth Indicators. Of all the nutritional status indicators assessed (i.e. height for age, weight for height, weight for age, and growth rate), it was only low height for age (stunting) that was significantly associated negatively with CS. Since the set of variables accounted for only $26.1 \%$ of the variance in mean HAZ, this suggests that other confounders not known or not accounted for could influence child growth. This together with the cross-sectional nature of the study means that only associations, and not causation, are indicated.

Stunting remains a major public health concern in many countries including Ghana as it has negative consequences including increasing the risk of illness, irreversible body damage, and mortality in children. Public health planners will have to consider effective interventions to reduce stunting by having full knowledge of its determinants. It is against this backdrop that our finding that CS deliveries associate with stunting is relevant to the programme planning and collaboration among all practitioners (that is, clinicians, policymakers, public health experts, etc.)

4.2. Potential Mechanisms Linking Mode of Delivery and Stunting. The study findings suggest that there is an association between caesarean delivery (CD) and stunting in children though underlying biological mechanisms still remain unclear. However, the mode of delivery may adversely affect child growth through its influence on feeding practices. In the present study, we found that CD was associated negatively with infant feeding practices including timely initiation of breastfeeding and prelacteal feeding. For example, vagina-delivered infants were 2.1 times more likely to initiate breastfeeding within one hour of delivery.

Breastfeeding infants within one hour of birth ensures that the infant receives the colostrum, or "first milk," which is rich in protective factors. This is the rationale behind the WHO recommending that all mothers should be supported to initiate breastfeeding as soon as possible after birth, within the first hour after delivery [23]. If the child's immune system is compromised, then the child becomes vulnerable to infections that may affect growth and development. Many other studies have reported that CS birth negatively affects timely initiation of breastfeeding [13-18, 24, 25] and that late initiation of breastfeeding after one hour after birth is significantly associated with stunting [26].

There is also a growing body of evidence that demonstrates the importance of early establishment and diversity of gut microbiota for the prevention of risks in the offspring. It has been reported that babies delivered by CS are generally not exposed to their mother's vaginal and faecal microbiota and that the gut microbiome of such babies has low diversity and richness $[27,28]$. This microbiota helps to shape the initial composition of an infant's microbiota including that of the gut [27]. Findings from some other studies suggest that infants born by CS might have a gut microbiota that has a tendency to harvest more dietary nutrients, thereby predisposing them to increased risk of being overweight or obese $[29,30]$, and that persists through early adult life [31]. Malamitsi-Puchner at al. [32] reported that only vaginal delivery is associated with the production of cytokines implicated in neonatal immunity. This reduced immunity with children born through CS could account for the observed association with stunting.

During normal delivery, the contact with mothers' vagina serves as an important flora for the infant's gastrointestinal tract (GIT) colonization. But during CS, this direct contact is absent; hence, nonmaternally derived bacteria play a vital role in the intestinal colonization [33, 34]. Studies have suggested that the composition of the very first flora in an infant's GIT could have long-term consequences on infants, especially in breastfed infants.

Furthermore, there is epidemiologic evidence of an association between CS birth and increased body mass index (BMI) [35-37]. It must, however, be noted that the evidence for a causal relationship between CS birth and the subsequent risk for obesity and other health risks is not conclusive because there is still no compelling evidence to support a causal link between elective CS and childhood obesity [38].

It appears that both the nonphysiological start of GIT colonization by flora and absence of early dietary support caused by delayed initiation of lactation could account for the long-term effects on the nutrition of children including stunting. However, long-term prospective studies need to be carried out to establish the clinical relevance and impact of this association.

In this present study, maternal short stature, obesity, and low birth order were key determinants of CS delivery and these together can greatly influence stunting either prenatally or postnatally. For example, compared to third-order babies, first- and second-order babies were 2.3 and 2.4 times more likely of being delivered through caesarean section ( $\mathrm{AOR}=2.29$ and 2.39, respectively). Compared to women aged under 25 years, women who were at least 35 years had 4.871 odds of delivery through CS. It is, therefore, possible that some of these factors could jointly be influencing stunting indirectly through CS. From our results, some factors associated with CS were also independent predictors of low HAZ. For example, we found that the risk of C-section was elevated in short women compared to women of normal stature and shorter maternal height was also a risk factor for low HAZ.

4.3. Predictors of Height-for-Age Z-Score (HAZ). After controlling for potential confounding factors, children who were born through normal vaginal delivery had 0.121 higher HAZ standard units than their counterparts born through caesarean section $(p<0.0001)$. The most consistent factors associated with low height-for-age $\mathrm{Z}$-score (HAZ) were the mode of delivery (caesarean section), low birth weight, increasing child's age, sex of child (male), parity of the mother $(<2)$, mother's age $(<25$ years), low mother's height, and increasing birth order.

A search on the literature shows that very few studies have investigated the association between CS and child growth and at least two studies have collaborated the present finding that there is a significant association between stunting and mode of delivery $[39,40]$. 
As it has been reported in previous studies from different countries, the order of birth was one of the significant predictors of the child being stunted in this study population [41-44]. Children of at least third-order birth were more likely to be stunted than children of the first-order birth. A possible explanation for this association could be that food and other essential resources decrease with an increasing number of births in the household, thereby making it impossible to meet essential basic needs including adequate feeding and health care. Consistent with other studies, utilization of antenatal and postnatal care services is also reported to decrease with the higher-order birth [45-47], implying preventive health services are unlikely to be available for such children. The finding in this study and many others, therefore, suggests reducing the number of births and for that matter birth order may reduce child stunting.

Female children had a mean HAZ that was significantly higher than their male counterparts. This means that boys were more likely than girls to have low height for age (stunting), which is consistent with earlier studies reporting similar trends from sub-Saharan Africa [42, 48, 49]. The vulnerability of boys to stunted growth might be explained by the fact that boys are expected to grow at a slightly more rapid rate compared to girls and their growth is perhaps more easily affected by nutritional deficiencies or other diseases or exposures [50].

A unit increase in the age of child led to reduced HAZ of 0.206 standard units and was consistent with similar studies where increasing the age of the child was associated positively with stunting $[39,51-53]$.

One other key determinant of stunting was low birth weight as the results showed that children born with a low weight $(<2.5 \mathrm{~kg})$ were more likely to be stunted, in comparison to children with weight $\geq 2.5 \mathrm{~kg}$ at birth. This finding is consistent with reports from other countries including Ghana, Pakistan, Mexico, and Nepal [39, 54-56] and justifies the need to support interventions that seek to prevent intrauterine growth retardation, premature delivery for the prevention of stunting.

We also found that low maternal height below $145 \mathrm{~cm}$ (that is, short stature) increased the risk of low HAZ (stunting). This confirms earlier research findings that high maternal height $[52,57,58]$ is positively associated with improved child nutrition.

Children born to women aged at least 35 years had a higher mean HAZ compared to children born to women under 25 years. This finding is consistent with studies previously conducted in many countries including Nepal Pakistan and Mexico [39, 55, 59-61].

\section{Conclusions and Recommendations}

This study has found an association between CS delivery and stunting (low height-for-age z-scores), an adverse outcome that clinicians and patients should weigh when considering caesarean birth that is not medically indicated to help improve mother and child postnatal health outcomes.
Since timely initiation of breastfeeding rate was significantly higher among women who had vaginal birth compared with those who had CS, it is highly recommended that postcaesarean practices such as rooming-in and skin-to-skin contact should be promoted in all health delivery facilities.

5.1. Limitations of the Study. This study was retrospective in nature and so responses provided depended on the mother's recall memory which can introduce measurement bias. The cross-sectional nature of the study also makes it difficult to demonstrate cause-and-effect relationships. Notwithstanding this, we have provided important insights into the relationship between caesarean birth and stunting.

$\begin{array}{ll}\text { Abbreviations } \\ \text { ANC: } & \text { Antenatal care } \\ \text { AOR: } & \text { Adjusted odds ratio } \\ \text { BMI: } & \text { Body mass index } \\ \text { CI: } & \text { Confidence interval } \\ \text { COR: } & \text { Crude odds ratio } \\ \text { CS: } & \text { Caesarean section } \\ \text { CWC: } & \text { Child Welfare Clinic } \\ \text { ENA: } & \text { The Emergency Nutrition Assessment } \\ \text { GIT: } & \text { Gastrointestinal tract } \\ \text { HAZ: } & \text { Height-for-age Z-score } \\ \text { IFI: } & \text { Infant feeding index } \\ \text { SMART: } & \text { Standardized Monitoring and Assessment of } \\ & \text { Relief and Transitions } \\ \text { WAZ: } & \text { Weight-for-age Z-score } \\ \text { WHZ: } & \text { Weight-for-height Z-score } \\ \text { WHO: } & \text { World Health Organization. }\end{array}$

\section{Data Availability}

The quantitative data presented in the form of SPSS used to support the findings of this study are included within the supplementary information files.

\section{Conflicts of Interest}

The authors declare that they have no conflicts of interest.

\section{Authors' Contributions}

MS and AYH conceived the study, participated in its design, and contributed significantly to the acquisition of data. MS did the analysis and interpretation of data and together with $\mathrm{AYH}$, drafted the manuscript, and revised it critically for important intellectual content. Both the authors read and approved the final draft.

\section{Acknowledgments}

The authors wish to acknowledge with gratitude the contribution of the data collection team whose hard work and commitment led to successful conduct of this study. The cooperation and support of mothers and caregivers who 
took time off from their busy schedules to respond to the interviewers are very much appreciated.

\section{Supplementary Materials}

The supplementary materials submitted along with the manuscript were actually the data set supporting the findings. (Supplementary Materials)

\section{References}

[1] R. E. Black, C. G. Victora, S. P. Walker et al., "Maternal and child undernutrition and overweight in low-income and middle-income countries," The Lancet, vol. 382, no. 9890, pp. 427-451, 2013.

[2] WHO, Levels and Trends in Child Malnutrition, WHO, Geneva, Switzerland, 2018, http://www.who.int/nutgrowthdb/ 2018-jmebrochure, pdf.

[3] L. Liu, H. L. Johnson, S. Cousens et al., "Global, regional, and national causes of child mortality: an updated systematic analysis for 2010 with time trends since 2000," The Lancet, vol. 379, no. 9832, pp. 2151-2161, 2012.

[4] World Health Organization, Global Nutrition Targets 2025, World Health Organization, Geneva, Switzerland, 2014.

[5] R. E. Black, L. H. Allen, Z. A. Bhutta et al., "Maternal and child undernutrition: global and regional exposures and health consequences," The Lancet, vol. 371, no. 9608, pp. 243-260, 2008.

[6] Ghana statistical service (GSS), Ghana health service (GHS), and ICF international, 2015. Ghana Demographic and Health Survey 2014, GSS, GHS, and ICF International, Rockville, MD, USA, 2015.

[7] S. Grantham-McGregor, Y. B. Cheung, S. Cueto, P. Glewwe, L. Richter, and B. Strupp, "Developmental potential in the first 5 years for children in developing countries," The Lancet, vol. 369, no. 9555, pp. 60-70, 2007.

[8] G. Danaei, K. G. Andrews, C. R. Sudfeld et al., "Risk factors for childhood stunting in 137 developing countries: a comparative risk assessment analysis at global, regional, and country levels," PLoS Medicine, vol. 13, no. 11, Article ID e1002164, 2016.

[9] WHO, "WHO Statement on caesarean section rates," Reproductive Health Matters, vol. 23, no. 45, pp. 149-150, 2015.

[10] Ghana Statistical Service, "Ghana 2003: results from the demographic and health survey," Studies in Family Planning, vol. 36, pp. 158-162, 2003.

[11] J. Ye, A. P. Betrán, M. Guerrero Vela, J. P. Souza, and J. Zhang, "Searching for the optimal rate of medically necessary cesarean delivery," Birth, vol. 41, no. 3, pp. 237-244, 2014.

[12] S. Shabnam, Caesarean Section Delivery in India: Causes and Concerns, Research Scholar, Jawaharlal Nehru University, New Delhi, India, 2009, http://iussp.org/sites/default/files/ event_call_for_papers/Caesarean_section_delivery_in_India_ $0 . p d f$.

[13] A. Belachew, "Timely initiation of breastfeeding and associated factors among mothers of infants age 0-6 months old in Bahir Dar City, Northwest, Ethiopia, 2017: a community based cross-sectional study," International Breastfeeding Journal, vol. 14, no. 5, 2019.

[14] T. Tewabe, "Timely initiation of breastfeeding and associated factors among mothers in Motta town, East Gojjam zone, Amhara regional state, Ethiopia, 2015: a cross-sectional study," BMC Pregnancy and Childbirth, vol. 16, p. 314, 2016.
[15] T. M. B. Esteves, R. P. Daumas, M. I. C. D. Oliveira, C. A. D. F. D. Andrade, and I. C. Leite, "Factors associated to breastfeeding in the first hour of life: systematic review," Revista de Saúde Pública, vol. 48, no. 4, pp. 697-708, 2014.

[16] H. J. Rowe-Murray and J. R. Fisher, "Baby friendly hospital practices: cesarean section is a persistent barrier to early initiation of breastfeeding," Birth, vol. 29, no. 2, pp. 124-131, 2002.

[17] C. S. Boccolini, M. L. D. Carvalho, M. I. C. D. Oliveira, M. D. C. Leal, and M. S. Carvalho, "Fatores que interferem no tempo entre o nascimento e a primeira mamada," Cadernos de Saúde Pública, vol. 24, no. 11, pp. 2681-2694, 2008.

[18] E. Prior, S. Santhakumaran, C. Gale, L. H. Philipps, N. Modi et al., "Breastfeeding after cesarean delivery: a systematic review and meta-analysis of world literature," The American Journal of Clinical Nutrition, vol. 95, no. 5, pp. 1113-1135, 2012.

[19] J. Neu and J. Rushing, "Cesarean versus vaginal delivery: longterm infant outcomes and the hygiene hypothesis," Clinics in Perinatology, vol. 38, no. 2, pp. 321-331, 2011.

[20] World Health Organization, WHO Child Growth Standards: Methods and Development: Length/height-For-Age, WeightFor-Age, Weight-For-Length, Weight-For-Height and Body Mass Index-For-Age, WHO, Geneva, Switzerland, 2006.

[21] D. Filmer and L. H. Pritchett, "Estimating wealth effects without expenditure data-or tears: an application to educational enrollments in states of India," Demography, vol. 38, no. 1, pp. 115-132, 2001.

[22] WHO, WHO Child Growth Standards: Length/Height-ForAge, Weight-for-Age, Weight-for-Length, Weight-for-Height and Body Mass Index-for-Age: Methods and Development, WHO, Geneva, Switzerland, 2006.

[23] World Health Organization, Indicators for Assessing Infant and Young Child Feeding Practices: Part 1: Definitions: Conclusions of a Consensus Meeting, WHO, Washington DC, USA, 2008.

[24] K. G. Dewey, L. A. Nommsen-Rivers, M. J. Heinig, and R. J. Cohen, "Risk factors for suboptimal infant breastfeeding behavior, delayed onset of lactation, and excess neonatal weight loss," Pediatrics, vol. 112, no. 3, pp. 607-619, 2003.

[25] K. C. Evans, R. G. Evans, R. Royal, A. J. Esterman, and S. L. James, "Effect of caesarean section on breast milk transfer to the normal term newborn over the first week of life," Archives of Disease in Childhood Fetal and Neonatal Edition, vol. 88, no. 5, pp. F380-F382, 2003.

[26] B. Batiro, T. Demissie, Y. Halala, and A. A. Anjulo, "Determinants of stunting among children aged 6-59 months at Kindo Didaye woreda, Wolaita Zone, Southern Ethiopia: unmatched case control study," PLoS One, vol. 12, no. 12, Article ID e0189106, 2017.

[27] M. G. Dominguez-Bello, E. K. Costello, M. Contreras et al., "Delivery mode shapes the acquisition and structure of the initial microbiota across multiple body habitats in newborns," Proceedings of the National Academy of Sciences, vol. 107, no. 26, pp. 11971-11975, 2010.

[28] M. B. Azad, T. Konya, H. Maughan et al., "Gut microbiota of healthy Canadian infants: profiles by mode of delivery and infant diet at 4 months," Canadian Medical Association Journal, vol. 185, no. 5, pp. 385-394, 2013.

[29] H. M. Tun, S. L. Bridgman, R. Chari et al., "Roles of birth mode and infant gut microbiota in intergenerational transmission of overweight and obesity from mother to offspring," JAMA Pediatrics, vol. 172, no. 4, pp. 368-377, 2018. 
[30] R. Jumpertz, D. S. Le, P. J. Turnbaugh et al., "Energy-balance studies reveal associations between gut microbes, caloric load, and nutrient absorption in humans," The American Journal of Clinical Nutrition, vol. 94, no. 1, pp. 58-65, 2011.

[31] C. Yuan, A. J. Gaskins, A. I Blaine et al., "Association between cesarean birth and risk of obesity in offspring in childhood, adolescence, and early adulthood," JAMA Pediatrics, vol. 170, Article ID e162385, 2016.

[32] A. Malamitsi-Puchner, E. Protonotariou, T. Boutsikou, E. Makrakis, A. Sarandakou, and G. Creatsas, "The influence of the mode of delivery on circulating cytokine concentrations in the perinatal period," Early Human Development, vol. 81, no. 4, pp. 387-392, 2005.

[33] S. Dogra, O. Sakwinska, S.-E. Soh et al., "Dynamics of infant gut microbiota are influenced by delivery mode and gestational duration and are associated with subsequent adiposity," MBio, vol. 6, no. 1, pp. e02419-e02414, 2015.

[34] G. Biasucci, B. Benenati, L. Morelli, and E. Bessi, "Cesarean delivery may affect the early biodiversity of intestinal bacteria 1, 2," The Journal of Nutrition, vol. 2, no. 138, pp. 1796-1800, 2008.

[35] R. Sutharsan, M. Mannan, S. A. Doi, and A. A. Mamun, "Caesarean delivery and the risk of offspring overweight and obesity over the life course: a systematic review and biasadjusted meta-analysis," Clinical Obesity, vol. 5, no. 6, pp. 293-301, 2015.

[36] K. Darmasseelane, M. J. Hyde, S. Santhakumaran, C. Gale, and N. Modi, "Mode of delivery and offspring body mass index, overweight and obesity in adult life: a systematic review and meta-analysis," PLoS One, vol. 9, Article ID e87896, 2014.

[37] S. Kuhle, O. S. Tong, and C. G. Woolcott, "Association between caesarean section and childhood obesity: a systematic review and meta-analysis," Obesity Reviews, vol. 16, no. 4, pp. 295-303, 2015.

[38] G. Masukume, S. M. O’Neill, P. N. Baker, L. C. Kenny, S. M. B. Morton, and A. S. Khashan, "The impact of caesarean section on the risk of childhood overweight and obesity: new evidence from a contemporary cohort study," Scientific Reports, vol. 8, Article ID 15113, 2018.

[39] R. Tiwari, L. M. Ausman, and K. E. Agho, "Determinants of stunting and severe stunting among under-fives: evidence from the 2011 Nepal demographicand health survey," BMC Pediatrics, vol. 14, no. 1, p. 239, 2014.

[40] B. J. Akombi, K. E. Agho, J. J. Hall, D. Merom, T. Astell-Burt et al., "Stunting and severe stunting among children under-5 years in Nigeria: a multilevel analysis," BMC Pediatrics, vol. 17, no. 1, p. 15, 2017.

[41] R. Mosfequr, "Association between order of birth and chronic malnutrition of children: a study of nationally representative Bangladeshi sample," Cadernos de Saúde Pública, vol. 32, no. 2, Article ID e00011215, 2016.

[42] C. Marston and J. Cleland, "Do unintended pregnancies carried to term lead to adverse outcomes for mother and child? An assessment in five developing countries," Population Studies, vol. 57, no. 1, pp. 77-93, 2003.

[43] R. E. A. Khan and M. A. Raza, "Nutritional status of children in Bangladesh: measuring composite index of anthropometric failure (CIAF) and its determinants," Pakistan Journal of Commerce and Social Sciences, vol. 8, pp. 11-23, 2014.

[44] C. Shapiro-Mendoza, B. J. Selwyn, D. P. Smith, and M. Sanderson, "Parental pregnancy intention and early childhood stunting: findings from Bolivia," International Journal of Epidemiology, vol. 34, no. 2, pp. 387-396, 2005.
[45] G. A. Fekadu, F. Ambaw, and S. A. Kidanie, "Facility delivery and postnatal care servicesuse among mothers who attended four ormore antenatal care visits in Ethiopia:further analysis of the 2016 demographicand health survey," BMC Pregnancy and Childbirth, vol. 19, no. 64, 2019.

[46] T. M. Tamang, "Factors associated with completion of continuum of Care forMaternal Health in Nepal," in Proceedings of the IUSSP XXVIII International Population Conference, Cape Town, South Africa, November 2017.

[47] W. Wang and R. Hong, "Levels and determinants of continuum of care formaternal and newborn health in Cambodiaevidence from a population-based survey," BMC Pregnancy and Childbirth, vol. 15, no. 1, p. 62, 2015.

[48] D. Gwatkin, S. Rutstein, K. Johnson, R. Pande, and A. Wagstaff, Socio-economic Differences in Health, Nutrition and Poverty, World Bank, Washington, DC, USA, 2000.

[49] World Health Organization, Child Growth Standards: Length/ height-For-Age, Weight-For-Age, Weight-For-Length, WeightFor Height and Body Mass Index-Forage, WHO, Geneva, Switzerland, 2006.

[50] J. U. Condo, A. Gage, N. Mock, J. Rice, and T. Greiner, "Sex differences in nutritional status of HIV-exposed children in Rwanda: a longitudinal study," Tropical Medicine \& International Health, vol. 20, no. 1, pp. 17-23, 2015.

[51] R. Pongou, M. Ezzati, and J. Salomon, "Household and community socioeconomic and environmental determinants of child nutritional status in Cameroon," BMC Public Health, vol. 6, p. 98, 2006.

[52] M. Rahman, "Is unwanted birth associated with child malnutrition in Bangladesh?" International Perspectives on Sexual and Reproductive Health, vol. 41, no. 2, pp. 80-88, 2015.

[53] H. Kismul, P. Acharya, M. A. Mapatano, and A. Hatløy, "Determinants of childhoodstunting in the Democratic Republic of Congo: further analysis ofdemographicand health survey 2013-14," BMC Public Health, vol. 18, no. 1, p. 74, 2018.

[54] M. A. Saleemi, R. N. Ashraf, L. Mellander, and S. Zaman, "Determinants of stunting at 6,12, 24 and 60 months and postnatal linear growth in Pakistani children," Acta Paediatrica, International Journal of Paediatrics, vol. 90, no. 11, pp. 1304-1308, 2001.

[55] M. I. Varela-Silva, H. Azcorra, F. Dickinson, B. Bogin, and A. R. Frisancho, "Influence of maternal stature, pregnancy age, and infant birth weight on growth during childhood in Yucatan, Mexico: a test of the intergenerational effects hypothesis," American Journal of Human Biology, vol. 21, no. 5, pp. 657-663, 2009.

[56] M. Saaka and S. Z. Galaa, "Relationships between wasting and stunting and their concurrent occurrence in Ghanaian preschool children," Journal of Nutrition and Metabolism, vol. 2016, Article ID 4654920, 11 pages, 2016.

[57] E. Özaltin, K. Hill, and S. V. Subramanian, "Association of maternal stature with offspring mortality, underweight, and stunting in low- to middle-income countries," JAMA, vol. 303, no. 15 , pp. 1507-1516, 2010.

[58] O. Y. Addo, A. D. Stein, C. H. Fall et al., "Maternal height and child growth patterns," The Journal of Pediatrics, vol. 163, no. 2, pp. 549-554, 2013.

[59] M. A. Saleemi, R. N. Ashraf, L. Mellander, and S. Zaman, "Determinants of stunting at 6, 12, 24 and 60 months and postnatal linear growth in Pakistani children," Acta Paediatrica, vol. 90, no. 1, pp. 1304-1308, 2001.

[60] B. Akombi, K. Agho, J. Hall, N. Wali, A. Renzaho, and D. Merom, "Stunting, wasting and underweight in subsaharan Africa: a systematic review," International Journal of 
Environmental Research and Public Health, vol. 14, no. 8, p. 863, 2017.

[61] S. Abeway, B. Gebremichael, R. Murugan, M. Assefa, and Y. M. Adinew, "Stunting and its determinants among children aged 6-59 Months in northern Ethiopia: a cross-sectional study," Journal of Nutrition and Metabolism, vol. 2018, Article ID 1078480, 8 pages, 2018. 